\title{
A Study on the Design of Wuhan gifts based on Wu Han impression Hong PENG, Shan-Shan LI*
}

\author{
Wuhan University of Science and Technology, 430065
}

408783104@qq.com

Key words: Wuhan impression, Wuhan gift, Product design.

\begin{abstract}
Purposes Promoting Wuhan's economic development can also enhance Wuhan's external influence and enhance Wuhan's "design capital" taste. Process and method Wuhan is rich in tourism resources and has distinct regional characteristics. "Wuhan impression" is also complex and varied. Based on this, this study, starting from the city image and city culture of Wuhan, deeply analyzes the connotation and historical mission of "city gift", and transforms cultural resources into cultural productivity. Conclusion It is considered that the gift of Wuhan should reflect the development level of Wuhan's social culture and economy, and it is the comprehensive embodiment of the city's strength.
\end{abstract}

As we all know, city gift is the carrier of city image. The dissemination of local culture through urban gifts has gradually become the focus of the times. Because of the diversity of "Wuhan impression", people have different understanding of "Wuhan impression", and its definition and classification standards are difficult to be unified. Therefore, the present design of Wuhan gift based on the impression of Wuhan is complicated and varied. This study classifies and combs the "Wuhan impression" and "Wuhan gift" through detailed data collection, network questionnaire and other methods.

\section{Investigation and Analysis of "Impression of Wuhan"}

Wuhan has diverse historical allusions, rich human resources, beautiful ecological environment, and has a unique temperament and enthusiasm, positive character. There are numerous objects and cultural connotations in Wuhan impression.

"Impression of Wuhan" is the influence of Wuhan's urban culture on the audience and the expression and expression of the urban manager's concept. Wuhan culture contains material culture and non material culture, material culture is a tangible object, such as material entities such as urban architecture, landscape, public facilities, and other spiritual culture, such as social psychology, values, morality, art, law, religion, custom, life style and so on.

From the history to the future, from the history to the future, the regional advantages of the thoroughfare of the nine provinces are the tolerance and the memory of the Wuhan culture. The city culture of the rivers and lakes converge with the elite education of the colleges and universities, and the tourism resources of Wuhan are complementary to the red culture, and the industrial system of the big Wuhan has changed to the high-tech Optics Valley and the financial port, and many other Wuhan impressions.

In the study of Wuhan tourism souvenir design under the background of creative industry, the author puts forward the ideas of the design of tourism souvenirs based on the tourism resources of Wuhan, which is based on the background of the creative industry. The author divides Wuhan tourism resources into four categories: the tourist attractions of Wuhan, represented by the Yellow Crane Tower, the regional cultural resources of Wuhan, led by $\mathrm{Chu}$ culture, and the modern revolution of Wuchang Uprising. Cultural resources; tourism resources such as Wuhan University.

The research group collected people's perceptions of Wuhan and Wuhan through the web questionnaire. A total of 150 questionnaires were distributed, and 132 valid questionnaires were collected. According to statistics, what is the first thing you want to think about when we mention Wuhan? In $54.5 \%$ of the respondents chose the hot dry noodles, $34.1 \%$ of the respondents chose 
Yellow Crane Tower. It can be seen from here that most people are very impressed with the food, and the hot dry noodles in Wuhan have become the representative of the Wuhan food, and the Yellow Crane Tower as a landmark building in Wuhan is well deserved.

Wuhan remains and other processes, such as Han Embroidery, Huangmei pick flower, Yangxin cloth paste, sugar painting, wood carving, pine stone carving, golden jade craft and other folk crafts; Wuhan Taoism (Changchun view), Buddhism (Guiyuan Buddhist Temple), Islam (mosque), Christ Church (Shanghai Road Temple) and other religious tourism make Wuhan city more impress, the combination of pluralistic civilization makes this city Glittering and shining.

\section{An Analysis of the "Wuhan Gift"}

Not only is Wuhan, but many tourist cities throughout the country lack or highlight the differentiated design of urban gifts. At present, the research on the city gift of Wuhan has a keyword search for tourist souvenirs in the context of the creative industry, the research on the design of Wuhan tourist souvenirs based on the city landmark, the development and design of tourist souvenirs. In these documents, the researchers analyzed the places from Wuhan representative things to Wuhan souvenirs to improve, and made the products with "ideas", which showed that the research on Wuhan impression and "Wuhan gift" was on the right track. But from academic to practical design, manufacturing, production and sales, and the establishment of brand creation, the study of "Wuhan gift" needs to be further explored.

We believe that the design of "Wuhan gift" must be distinct, and should be combined with the characteristic culture and modern design of Wuhan. The present gift culture of Wuhan is not prominent enough. It is all kinds of souvenir stamps, tour guides, Ming letters, and so on, headed by the hot dry noodles and the Yellow Crane Tower. These tourist products, headed by the hot dry surface and the Yellow Crane Tower, are old, simple in type, simple in technology, old materials, and more unused "city impression" cultural resources are being slowly forgotten. These are the key elements that restrict the development of the urban gift design and manufacturing industry. Many of the former brilliant intangible cultural heritage is facing an endangered dilemma. Most traditional industries related to tourist souvenirs are struggling. The environment of gift design and production is still at the initial stage in China. The tourist city, represented by Beijing and Shanghai, has turned from the low design content and the homogeneous product category to the urban brand oriented system design stage because of its tourism industry and the support of the creative industry.

\section{The Design and Analysis of "Wuhan Gift"}

Combined with previous studies, the research group believed that three aspects of research and design practice should be carried out.

First of all, from the subject matter, it should not be limited to the familiar impression of the city landmarks and scenic spots. Secondly, from the type, the consumption population is different, and the demand for "Wuhan gift" is different, according to specific classification and specific analysis. Daily necessities and creative products are the most popularized products in Wuhan gift design. It is the carrier to promote the good expression of the city image of Wuhan. Finally, from the material and technology, we should find new innovation points from the traditional Wuhan technology, try to achieve the "new technology", effectively use the remains of Wuhan, or Wuhan 8 plus 1 city circles.

\section{The Creative Theme of "Wuhan Gift"}

Every impression of Wuhan can be used as a creative theme of "Wuhan gift". Oto Seiichi of University of the Arts in Tokyo, Japan, once said, "the design of Japan in twentieth Century is the economic design, and the Japanese design in twenty-first Century is a cultural design." Therefore, we have reason to believe that the success of cultural design is the criterion to test whether the contemporary design is successful. Cultural and creative industries are emerging industries with the core of creativity in the context of economic globalization. The developed countries, such as the 
United States and Japan, have their own set of relatively perfect cultural and creative systems. We can often see many of the products produced under this cultural system. These cultures have far-reaching effects on the whole world, especially the young people, and have gained a large number of people. Young people's pursuit and love. Based on the series of stationery design derived from the form of Wuhan Yangtze River bridge, the slogan of "big river, big river and big Wuhan" in Wuhan is integrated into it. Through the many geographical features of the Wuhan Bridge and the most famous of Yangtze River bridge, a series of stationery is designed abstractly by the steel structure characteristics of the first bridge of the Yangtze River. Another important theme Yellow Crane Tower is the "impression of Wuhan" in the survey. In the design practice, the Yellow Crane and the silhouette of the mountains are integrated into the candles. When the candles begin to burn, the yellow crane will disappear gradually with the melting of the candles. Finally, only the Yellow Crane Tower is left in the empty cup, and the person is placed in "the Yellow Crane Tower" and "the Yellow Crane never returns." In view, see Fig.1.

Similar to the classical architecture of Wuhan, the landmark architecture into Wuhan gift design, there are many, through these cases, we can feel the historical sense of Wuhan Yangtze River bridge and the cultural sense of the Yellow Crane Tower as the background of the ancient poetry, the cultural promotion of the story, and the good expression of the city image of Wuhan. Fig. 2: the design of the fan, the other is the elements of Wuhan in Yangtze River bridge. The two sides of the fan leaf are the shape of the bridge bridgehead. The upper part of the fan is the supporting form between the two layers of the bridge, and the lower part is the spray pattern of the Yangtze River water. This bamboo fan is made of beech, sandalwood, bamboo and other materials. The combination of these different materials and the modern technology makes the fan with bamboo as the raw material more delicate and elegant, and can also show the majesty of the Yangtze River bridge in Wuhan.

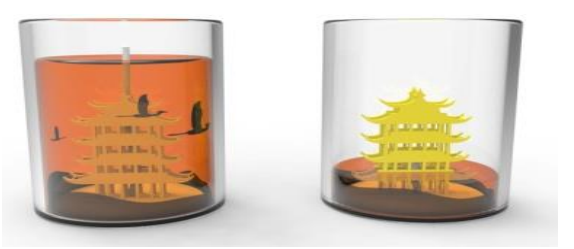

Fig. 1 The design of candles based on the form of Yellow Crane Tower, As the candle melts, only the Yellow Crane Tower is left in the empty cup (Designed by WUST's students)

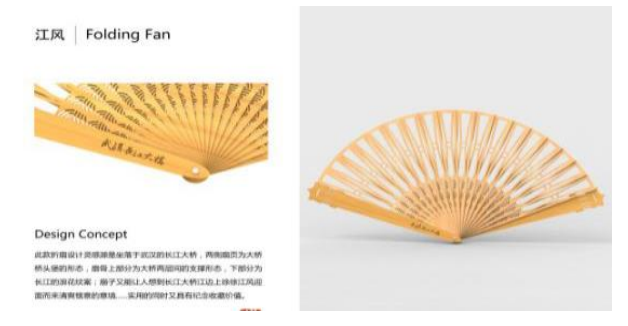

Fig. 2 Jang Feng Folding fan(Designed by WUST's students)

The abstract design and image expression of "Wuhan impression" will make the cultural elements of Wuhan reasonably extracted and applied to various types of product design, not limited to the creation of products. This process is not simply used and copied, but abstracts the cultural connotation of the city and the personality characteristics of the Wuhan people, and the form which is too concrete does not adapt to the modern aesthetic and scale application.

The abstract technique of deformation makes the specific objects sublimate from physical form to the concise summary of the art form, which forms close to the object, but is not entirely an abstraction of its image. From urban map to urban topographic map, from the urban topographic map to the simple grid diagram, everyone has the most basic impression of the city. When people walk in or out of a city, the first place to arrive is the railway station, which is the landmark building 
of the city. For example, figure 3 is an ear line designed for the basic elements of the Wu Han Railway Station. It has a strong regional map of Wu Han Railway Station as well as modern ideas no one can think of a map of Wuhan in your ear line. It embodies the regional culture, elements and symbols of Wuhan, the design of the form and form, and the concept of cultural promotion with stories and allegations.
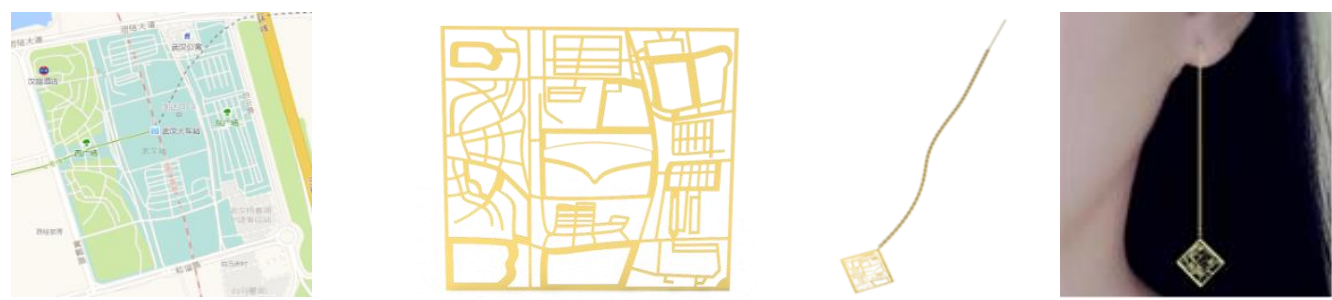

Fig.3 Pattern ornaments of Wu Han Railway Station (Designed by Li Shanshan)

The theme of Creative products has been extremely extensive in the modern design. It not only holds the traditional landmark building, but also has abstract design connotation. The project group is carrying out the design of the Yellow Crane Tower form series. It has reached more than 100 plans. It can be simply extracted and used, and the poetic Yellow Crane Tower is transformed into different industrial products and cultural and creative products, simplify what is complicated. The theme of "Wuhan impression" gift design is not very rich, but there is no difference.

\section{The Type of "Wuhan Gift"}

1) Classified according to the different target population. For example, international, government, business, friends and family exchange, Table 1is based on the target population's material, creativity and theme needs.

Table 1 Target crowd's gift demand (Designed by Li Shanshan)

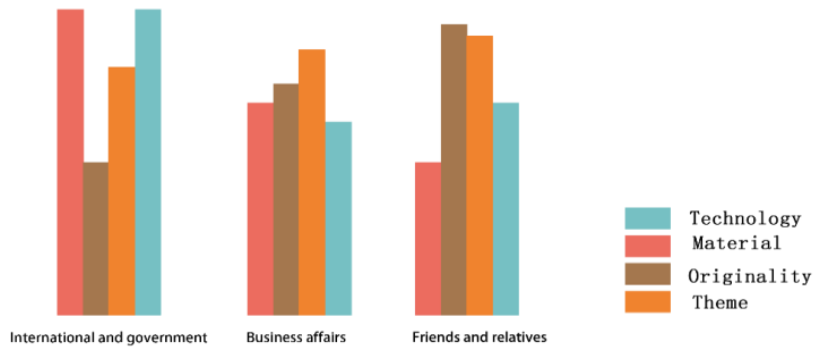

From the above table, we know that gifts between international and government should not only have unique historical and cultural connotations, but also match the corresponding material or the technology of collection value. Such as precious heavy metals, rare materials, unique technology, etc., in order to embody the importance of mutual relationship. In Figure 4, 5, 6, 7, is the "Millennium song brocade, hundred years long Kai" delivery ceremony as the country leaders present. The material, technology and other gifts, etc., itself does not seek creative law-abiding, new in order to be different.

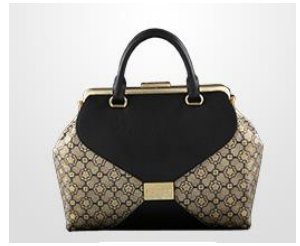

Fig.4Gift to the Prime Minister of South Africa

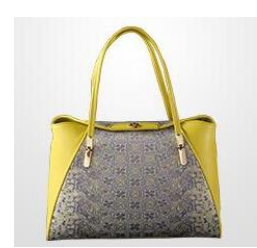

Fig.5 Gift to the governor of Papua New Guinea 

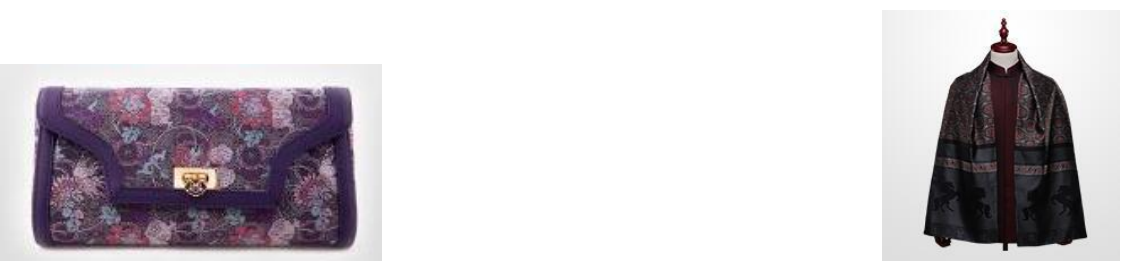

Fig.6 Gift to the prime minister's wife of Malaysia Fig.7Gift to Michael Dale, the founder of DELL

Business gifts usually don't need special valuable materials, but they must have unique historical and cultural connotations and creativity. As for the silk scarf design of figure 8, the silhouette material of the permanent building of the Huang Jia Lake Campus of Wuhan University of Science and Technology is incorporated into the silk scarf. It can not only allow the students who have graduated to send their own feelings of Miss, but also can be sent to the related units, or gifts between relatives and friends as a campus souvenir.

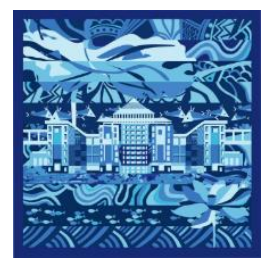

Fig.8 Gift to Xu Jiayin

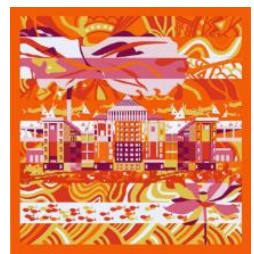

Fig. 9 Minimalist Bracelet (Designed by Wang Pingzhen)

Usually, gifts between friends and family need unique cultural connotations, and they should be creative and practical. The project group will deconstruct the Wuhan map restructure design series of products, of which figure 9 is a creative bracelet, the "Wuhan terrain" along the side, helping other tourists to understand the regional distribution of Wuhan. The material can be made of silver.

Table 2 (Designed by Li Shanshan)

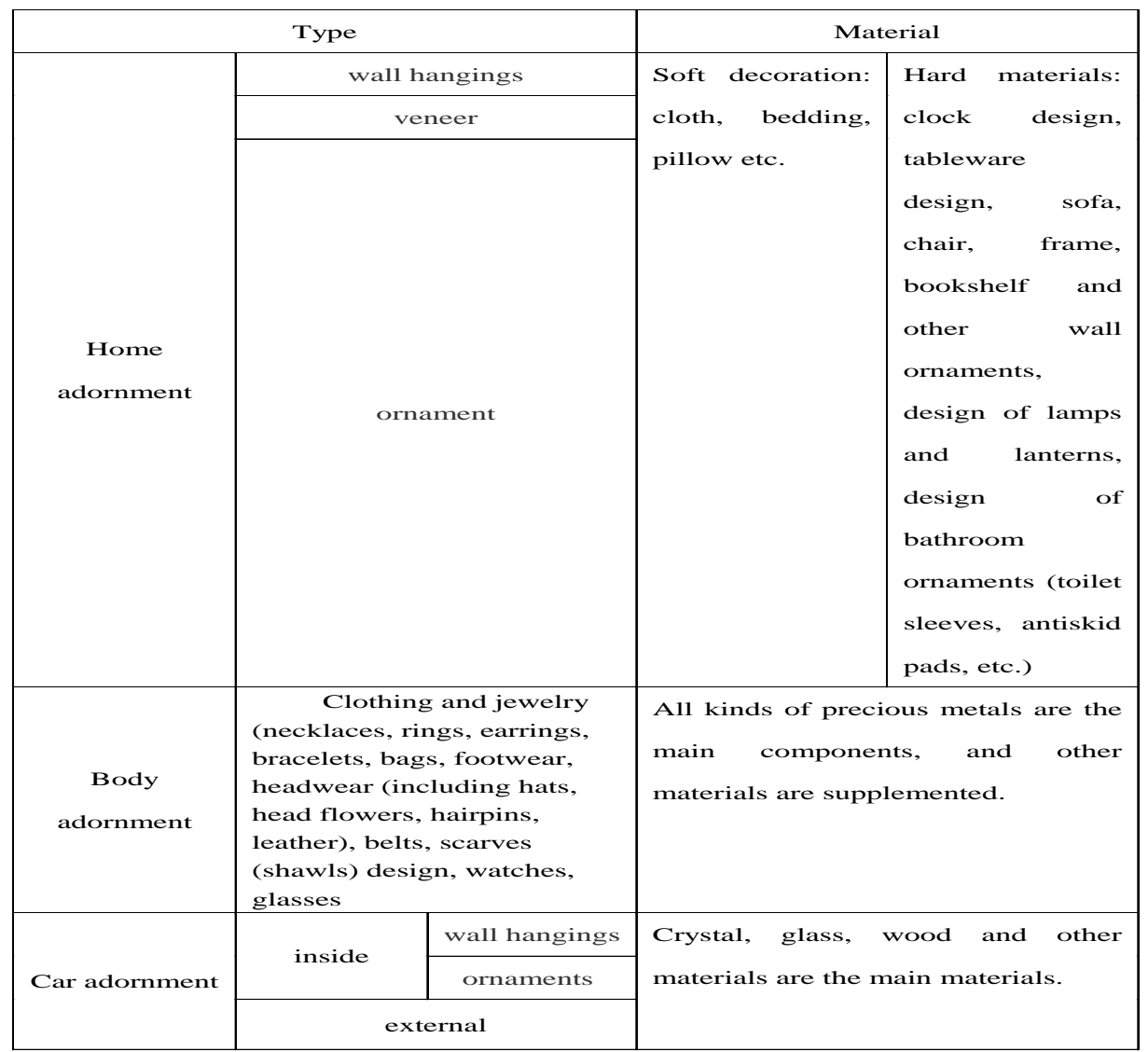


2) According to the type of ornaments to divide. The generalized ornaments are used for decoration, and the narrow ornaments can be divided into family decorations, body decorations, car mounted accessories, etc. (see table two).

As an indispensable product of people's daily life, the item group has a very high frequency of use and attention, so as the main force in the design of Wuhan gift, ornaments can play a better promotion effect. Figure 10 is the design of tableware in home ornaments. This tea set is evolved from the allusions of "high mountain and water" in Wuhan. It not only embodies the artistic conception of high mountains and rivers, but also coincides with tea culture with tea friends.

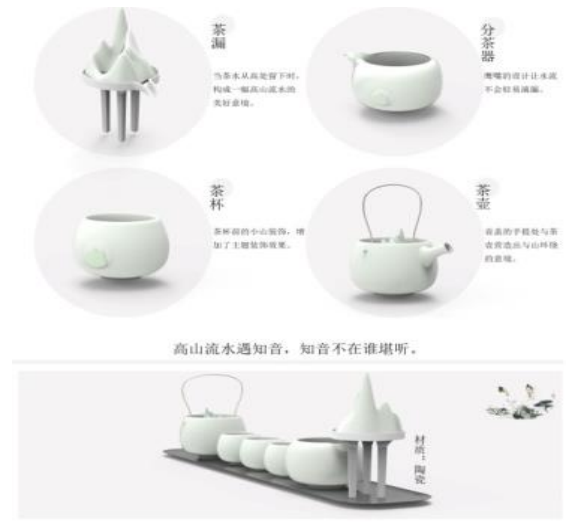

Fig. 10 Minimalist t Tea set (Designed by Zhang Zhanwei)

To sum up, the design of the gift in Wuhan should be closely related to people's life, related to the city culture of Wuhan, and make the daily life interesting and dynamic, and have good scalability.

\section{The Material and Technological Innovation of "Wuhan Gift"}

As a gift, "Wuhan gift", in addition to the common tourist souvenirs, the difference design is an important link: the gift also needs to have a collection value or reflect the latest technology (or material) of the product of the period. For example, figure 11 is a $U$ disk designed to be born out of the bell tower of the Wuhan University of Science and Technology library. The U disk, which uses 3 color K gold (gold, platinum, rose gold), not only represents the new idea of campus creation, but also shows that the campus souvenirs do not need to stay on cheap, simple stationery. The hard texture materials are carefully designed and refined. After grinding, the whole U disk looks very fashionable. It can be used not only as a U disk, but also as an ornament. A multi-purpose U disk designed as a souvenir in Wuhan has played a promotional role in promoting the culture of Wuhan universities. Precious metals, instead of general U dish, can be used to create high quality products of gifts, which has the value of collection and permanent commemorative significance. Similarly, the promotion of 3D technology and the use of precious metals on consumables make it possible to customize DIY jewelry.

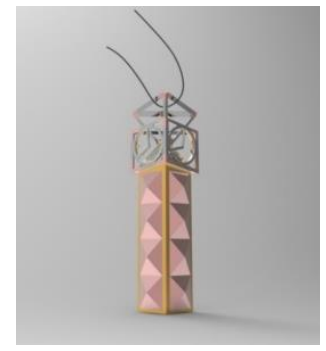

Fig. 11The Bell tower of WUST’ USB drive (Designed by Peng Hong)

We believe that gifts in Wuhan should not only preserve the essence of all kinds of skills, but also integrate cutting-edge technologies into non heritage skills. The older generation's wisdom is 
expressed in modern way, creating the new technology of "Wuhan gift". "Kao Gong Ji" said: "sometimes the sky is sometimes, the earth has the gas, the material has the beauty, the work is skillful, the combination of these four, then can be good." The innovation of materials and skills is to add to the product. Through the combination of material, technology and culture, the image of the product can be more prominent. We should advocate the combination of traditional culture and fashion culture, and dig deeper into local folk arts to make art popular among the few people in the past. For example, "Han Embroidery", once Shen Congwen said, this "Han" is not Wuhan "Han", but the Han Dynasty "Han", then its representative more meaningful, Wuhan from the decline of embroidery street to the revival of the Han embroidery workshop in Epiphyllum, is not a simple return to the traditional culture return signal, research, at present, embroidery workshop production The problem is too simple and traditional, the problem lies in the complexity of the process and the long time. It is not impossible to develop the embroidery craft of Han Embroidery to the related enterprises. It is not impossible to develop the embroidery craft of Han Embroidery to the related enterprises. It is necessary for the government and special funds to support the design of modern creative products using embroidery technology not only to reflect the aesthetic of this period, but also to the traditional culture. A good opportunity to upgrade and create new industries will be achieved. The research group uses traditional old embroidered pieces to design some materials, such as the design of ornamental vase, the design of necklace pendant, and the design of gloves, such as embroidered and cowhide. Moreover, the products based on the local culture must be different and have local characteristics.

Wuhan's technology enterprises get together in Optics Valley. Universities are also places for patent collection, but many patents fail to turn into productive forces or innovative products. Taking folk art - paper cutting as an example, we have repeatedly stressed the "fashion" treatment of folk art in teaching and scientific research so as to effectively inherit the traditional culture. In the research of the subject group, many "paper-cut" products with fashion characteristics are produced, such as the flavor of paper cutting with laser engraving machine on wool felt materials. The fashion lampshade, coasters, bags and other products are not only rich in visual effects, but also practical and meaningful. Similarly, there are screens, product packaging and so on.

Wuhan's technology enterprises get together in Optics Valley. Universities are also places for patent collection, but many patents fail to turn into productive forces or innovative products. Taking folk art - paper cutting as an example, we have repeatedly stressed the "fashion" treatment of folk art in teaching and scientific research so as to effectively inherit the traditional culture. In the research of the subject group, many "paper-cut" products with fashion characteristics are produced, such as the flavor of paper cutting with laser engraving machine on wool felt materials. The fashion lampshade, coasters, bags and other products are not only rich in visual effects, but also practical and meaningful. Similarly, there are screens, product packaging and so on.

To sum up, the traditional handicraft must be inherited and developed through modern transformation. Wuhan gift, through the integration of the non remains (such as Han Embroidery, etc.) and the most advanced technology, applies the latest black science and technology as the medium in the traditional materials, and continuously promotes the innovation of the non remains and technology in the process making, and further combines the cultural soft power of Wuhan with the economic and scientific and technological achievements of Wuhan. In the thought of handicraft, Mr. Hang said that the adaptability of human beings should be the premise of the process behavior. As a cultural form, the technology can be referred to the height of life philosophy.( Hang Jian, The idea of craft $[\mathrm{M}]$. Shandong pictorial press. 2001)

\section{Conclusion}

The design of "Wuhan gift" came from "Wuhan impression", and became a new impression of Wuhan as a modern product. The design of "Wuhan gift" not only takes into account the creative, cultural, and regional needs for different types of consumers, but also to make new designs and new themes into the public. We bring the "Wuhan impression" to every country, city and family, enhance Wuhan's external influence and further enhance Wuhan's urban taste. The gift of Wuhan is 
the development level of Wuhan's social culture and economy, and it is the comprehensive embodiment of the city's strength.

\section{References}

[1] Zhu Ziying. Hangzhou urban gift design research and practice [D]. The China Academy of Art, 2014.

[2] Yuan Yong. Design and research of tourist souvenirs in Wuhan under the background of creative industry [D]. Central China Normal University ,2012.

[3], Peng Fei. The conditions and evaluation of Wuhan's construction of the "middle triangle" tourist center city [D]. Central China Normal University, 2015.

[4] Guan Jiaqing, Sheng Yaqin. [J]. Design and development of art education on cultural symbols of Wuhan city gift based on 2014,05:216-217.

[5] Jia Xiang. Research on the classification and location of Wuhan cultural tourism resources [J]. North economic and trade, 2014,09:261-262.

[6] Tong Huan. Wuhan urban image design research [D]. Central China Normal University, 2007.

[7] Tu Yameng. Tourism souvenirs design and development of [D]. Hubei University of Technology, 2016.

[8] Peng Hong. The inheritance and application of the national folk decorative art in the regional tourist souvenirs. [J]. Art Panorama, 2015.5 P.

[9] Peng Hong. Study on Western folk art development of tourist souvenirs in Hubei [J]. Mangzhong Literature 2016.9.

[10] Peng Hong. Analyze the originality of the innovation design, [J]. Packaging engineering, 2012 (8).

[11] Zhu Jiadan. Application of national culture elements in industrial product design [J]. Science and technology information (Science and Teaching Research). 2008 (11)

[12] Peng Hong. The application and innovation of Chinese national art in fashion product design. [J]. art 100, 2012 (S2).

[13] Hang Jian, The idea of handicraft [M]. Shandong pictorial press. 2001 